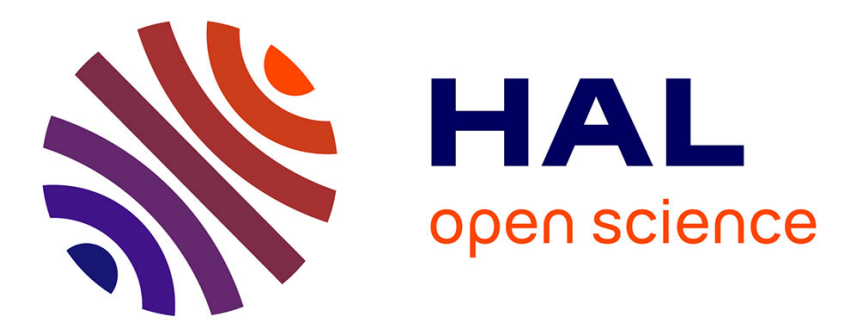

\title{
State of the art of High Temperature Power Electronics
} Cyril Buttay, Dominique Planson, Bruno Allard, Dominique Bergogne, Pascal Bevilacqua, Charles Joubert, Mihai Lazar, Christian Martin, Hervé Morel, Dominique Tournier, et al.

\section{- To cite this version:}

Cyril Buttay, Dominique Planson, Bruno Allard, Dominique Bergogne, Pascal Bevilacqua, et al.. State of the art of High Temperature Power Electronics. Microtherm, Jun 2009, Lodz, Poland. pp.8-17. hal-00413349

\section{HAL Id: hal-00413349 \\ https://hal.science/hal-00413349}

Submitted on 3 Sep 2009

HAL is a multi-disciplinary open access archive for the deposit and dissemination of scientific research documents, whether they are published or not. The documents may come from teaching and research institutions in France or abroad, or from public or private research centers.
L'archive ouverte pluridisciplinaire $\mathbf{H A L}$, est destinée au dépôt et à la diffusion de documents scientifiques de niveau recherche, publiés ou non, émanant des établissements d'enseignement et de recherche français ou étrangers, des laboratoires publics ou privés. 


\title{
State of the art of High Temperature Power Electronics
}

\author{
Cyril Buttay, Dominique Planson, Bruno Allard, Dominique Bergogne, \\ Pascal Bevilacqua, Charles Joubert, Mihai Lazar, Christian Martin, \\ Hervé Morel, Dominique Tournier, Christophe Raynaud \\ Université de Lyon, F-69622, France \\ CNRS, UMR5005, France, \\ INSA Lyon, Laboratoire Ampère, bâtiment L. de Vinci, 21 avenue Capelle \\ F-69621, France \\ cyril.buttayeinsa-lyon.fr \\ www . ampere-lab.fr
}

\section{Keywords}

High-temperature, Silicon carbide, Power electronics

\begin{abstract}
High temperature power electronics has become possible with the recent availability of silicon carbide devices. This material, as other wide-bandgap semiconductors, can operate at temperatures above $500^{\circ} \mathrm{C}$, whereas silicon is limited to $150-200^{\circ} \mathrm{C}$. Applications such as transportation or a deep oil and gas wells drilling can benefit. A few converters operating above $200^{\circ} \mathrm{C}$ have been demonstrated, but work is still ongoing to design and build a power system able to operate in harsh environment (high temperature and deep thermal cycling).
\end{abstract}

\section{Introduction}

The first part of this paper will describe some of the most prominent applications for high temperature power electronics. This is where high temperature-capable converters are enabler for new solutions, such as electrical actuators for jet engine.

The second part will give a short explanation on why wide-bandgap semiconductors are needed for high-temperature electronics, and why, among them, silicon carbide has been chosen.

Finally, we will see that a lot of work is still required to design a complete power converter (this include passive components, packaging, control circuits in addition to the active power devices).

\section{Applications for high-temperature power electronics}

"High temperature" means different things to different applications. In high voltage systems (such as power distribution), where silicon-based diodes or thyristors are limited to $125^{\circ} \mathrm{C}$ max- 
imum junction temperature, an ambient of $100^{\circ} \mathrm{C}$ would be considered insanely high, whereas running in an environment as high as $150^{\circ} \mathrm{C}$ is already pretty common for some automotive systems.

Here, we list a few applications that all currently require power electronic systems operating at temperatures above $200^{\circ} \mathrm{C}$ (sometimes a lot more!), with some details on their environment. However, please note that this list is not exhaustive. For example, applications such as electricity distribution can also benefit from high temperature systems.

\subsection{Aircrafts}

In order to reduce the complexity of wiring and piping of commercial aircrafts (which make use of hydraulic, pneumatic and electric actuators), manufacturers are moving towards the socalled "more electric architecture", which tends to use only electrical systems. For example, the MOET (More Open Electrical Technology) project, funded by the European research program FP6 [1], is focussed to "Validate scalable electrical networks up to 1MW considering new voltages and advanced concepts including system transformation of future air, actuation and electrical systems into all electrical solutions"

To achieve sufficient efficiency, electrical actuators should be driven through power electronics converters, in a distributed fashion [2]. Converters should be placed as close as possible to the actuator they control. This implies that some converters will be subject to harsh environment. For example, some of them will have to operate near the jet engine, with ambient temperature ranging from $-55^{\circ} \mathrm{C}$ to $225^{\circ} \mathrm{C}$ [2].

Obviously very high reliability is expected from these systems, despite long operating life (10 - 30 years) and frequent deep thermal cycling (several takeoff-landing per day).

\subsection{Automotive}

Even when considering "classical" vehicles (as opposed to hybrid or full electric cars), the cost of the electrical system is more than that of the internal combustion engine (ICE) and its associated transmission [3]. Under the hood, temperatures can reach or exceed $140^{\circ} \mathrm{C}$ (for example, the rectifier diodes at the back of the alternator can operate above $160^{\circ} \mathrm{C}$ junction temperature [4]). At the opposite, temperatures can drop to $-40^{\circ} \mathrm{C}$ in some places of the car.

In hybrid vehicles, it is possible to take advantage of the ICE cooling loop to extract heat from the power electronic systems, but the water can reach up to $120^{\circ} \mathrm{C}$ [3], so there is little headroom when working with 150 or $175^{\circ} \mathrm{C}$-limited silicon devices.

\subsection{Space exploration}

Space exploration is obviously a "niche" market, but it sets some seriously challenging goals [5]: surface temperature on Venus can reach 460 to $480{ }^{\circ} \mathrm{C}$. On Jupiter, temperature increases with depth (and pressure); and a few hundred kilometres down, the ambient temperature reaches $400^{\circ} \mathrm{C}$ and 100 bars, with a very aggressive atmosphere (winds around $200 \mathrm{~m} / \mathrm{s}$, hydrogen-rich chemical composition...).

Thermal cycling is also an issue as ambient temperatures can be as low as $-140^{\circ} \mathrm{C}$ during the night. 


\begin{tabular}{|c|c|c|c|c|c|c|c|}
\hline & \multicolumn{2}{|c|}{$\begin{array}{c}\text { "Classical" } \\
\text { semiconductors }\end{array}$} & \multicolumn{5}{|c|}{ wide-bandgap semiconductors } \\
\hline & $\mathrm{Si}$ & GaAs & 3C-SiC & $6 \mathrm{H}-\mathrm{SiC}$ & $4 \mathrm{H}-\mathrm{SiC}$ & $\mathrm{GaN}$ & Diamond \\
\hline Bandgap Energy $E_{g}(\mathrm{eV})$ & 1,12 & 1,4 & 2,3 & 2,9 & 3,2 & 3,39 & 5,6 \\
\hline Elec. mobility $\mu_{n}\left(\mathrm{~cm}^{2} \cdot \mathrm{V}^{-1} \cdot \mathrm{s}^{-1}\right)$ & 1450 & 8500 & 1000 & 415 & 950 & 2000 & 4000 \\
\hline Hole mobility $\mu_{p}\left(\mathrm{~cm}^{2} \cdot \mathrm{V}^{-1} \cdot \mathrm{s}^{-1}\right)$ & 450 & 400 & 45 & 90 & 115 & 350 & 3800 \\
\hline Critical elec. field $E_{C}\left(\mathrm{~V} . \mathrm{cm}^{-1}\right)$ & $3.10^{5}$ & $4.10^{5}$ & $2.10^{6}$ & $2,5 \cdot 10^{6}$ & $3.10^{6}$ & $5.10^{6}$ & $10^{7}$ \\
\hline Saturation velocity $v_{\text {sat }}\left(\mathrm{cm} . \mathrm{s}^{-1}\right)$ & $10^{7}$ & $2.10^{7}$ & $2,5.10^{7}$ & $2.10^{7}$ & $2.10^{7}$ & $2.10^{7}$ & $3.10^{7}$ \\
\hline Termal cond. $\lambda\left(\mathrm{W} . \mathrm{cm}^{-1} \cdot \mathrm{K}^{-1}\right)$ & 1,3 & 0,54 & 5 & 5 & 5 & 1,3 & 20 \\
\hline Dielectric constant $\varepsilon_{r}$ & 11,7 & 12,9 & 9,6 & 9,7 & 10 & 8,9 & 5,7 \\
\hline
\end{tabular}

Table I: Physical properties of "classical" and wide-bandgap semiconductors. Note that some of these materials exhibit anisotropic behaviour, so the values given here should just been considered indicative.

\subsection{Deep oil/gas extraction}

Requirements for these applications are quite different from the ones we have just seen: most systems here are expected to run continuously at high ambient temperature for 5 years or more, but without much thermal cycling. However, due to the high cost associated with stopping the exploitation (the power systems are located downhole, several kilometres deep), reliability must be excellent.

An example of use of power electronics is the electrical downhole gas compressor [6], designed to increase the production of gas wells by putting a compressor close to the gas reservoir. For this application, the ambient temperature is expected to reach $150^{\circ} \mathrm{C}^{1}$. For deep oil wells, temperature is expected to reach $225^{\circ} \mathrm{C}$, with a system lifetime of 5 years [7].

\section{Silicon carbide: the key enabler}

\subsection{Wide bandgap semiconductors for high temperature}

Some of the physical properties of several semiconductor materials are listed in table I. Silicon is, by far, the most used material in power electronic devices. The properties of galium arsenide (GaAs) are also given for reference, as this material is mainly used for very high-frequency applications. Power components made of silicon carbide (especially the $4 \mathrm{H}$ polytype) have become commercially available in recent years. Schottky-barrier diodes can be bought from many suppliers (Infineon, Cree, ST Microelectronics...) for a few euros, and controlled switches (JFET) are available as engineering samples. The advantages of this material, as well as of the other wide-bandgap materials in table I, are a higher critical field, a higher saturation velocity, and a lower intrinsic carrier density (due to the higher bandgap).

The advantages of wide-bandgap materials become clear in figure 1 . It can be seen that silicon devices rated above a few hundred volts cannot operate higher than $200^{\circ} \mathrm{C}$. Worse, highvoltage silicon components (such as $6.5 \mathrm{kV}$ IGBTs) are limited to an even lower junction temperature $\left(125^{\circ} \mathrm{C}\right.$ in this case). With wide-bandgap semiconductors, the operating area is a lot bigger, allowing very high-voltage (up to a hundred kilovolts) devices, operating at temperatures above $400^{\circ} \mathrm{C}$ or more.

\footnotetext{
${ }^{1}$ http://ior.senergyltd.com/issue13/research-development/smes/corac/
} 


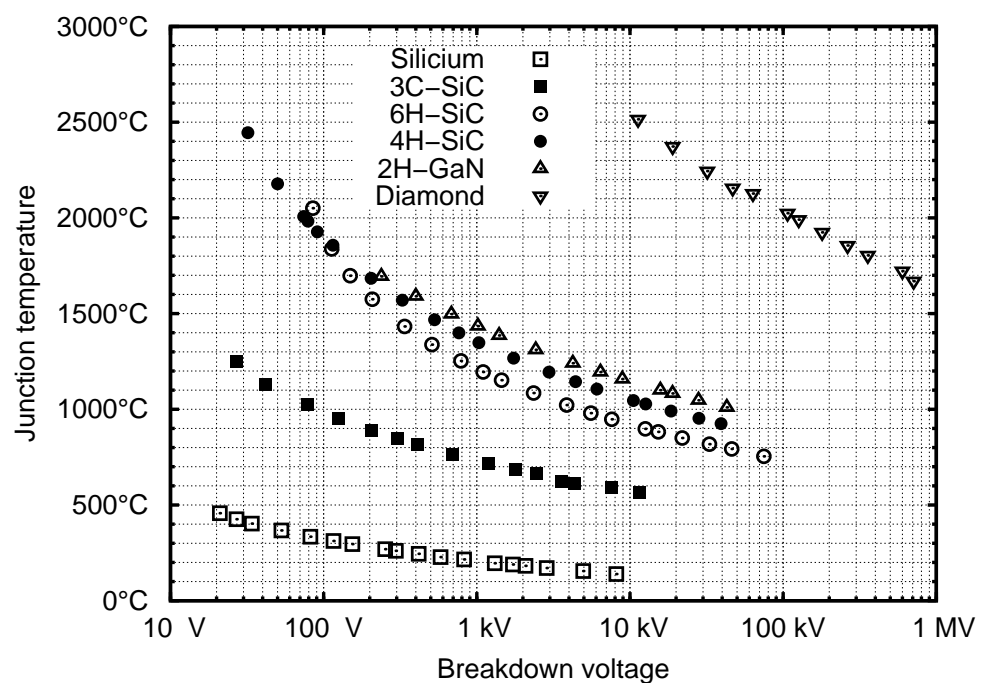

Figure 1: Thermal runaway limits for various semiconductors: This corresponds to the maximum operating temperature of an optimal structure (thickness, doping level) designed to sustain the voltage on the $\mathrm{x}$-axis (results obtained by simulation).

However, all materials have not reached the same technological maturity. Silicon technology is, of course, very well known, with very low cost material and very high yield production. $\mathrm{GaN}$ is, at the moment, available only as heterostructures with a thin layer of $\mathrm{GaN}$ on top of other materials (sapphire, silicon or $\mathrm{SiC}$ ). Therefore, it is not possible to build vertical devices, thus making this material less appealing for power applications. Diamond technology is currently at a very early stage, with no good quality wafers available, and a lot of process steps to be developed.

$\mathrm{SiC}$, in the other hand, has showed very good progress in recent years, with very good quality, up to 4 inches wafers now available from different manufacturers. This is why we will focus on this material in the remaining of this paper

\section{2 power devices for high temperature}

\subsubsection{Unipolar devices}

In silicon, unipolar devices (mainly Schottky Barrier Diodes and MOSFET) are not considered for operating voltage above a few hundred volts, because of their increase in resistivity. Silicon carbide, however, offers a much lower resistivity (respectively 100 and 2000 times lower for $6 \mathrm{H}$ an $4 \mathrm{H}$-polytypes [8] than a layer of silicon designed to sustain the same breakdown voltage), making unipolar devices a sensible choice up to around $10 \mathrm{kV}$. For high temperature applications, however, pure SBDs should be replaced by Junction Barrier Schottkies (JBS) to take advantage of a lower leakage current.

One of the advantages of unipolar devices is their speed, offering very low commutation losses due to the lack of recovery phenomenon [9]. Their conduction losses, however, are somewhat higher than that of their bipolar counterparts. The high temperature reliability of unipolar $\mathrm{SiC}$ devices has been found to be as good as that of Si-diodes [10]. 


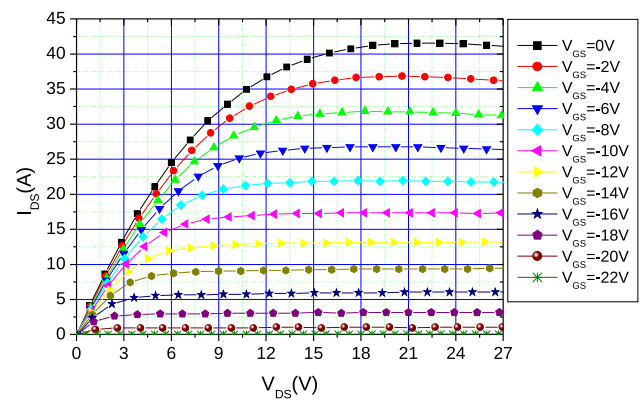

(a)

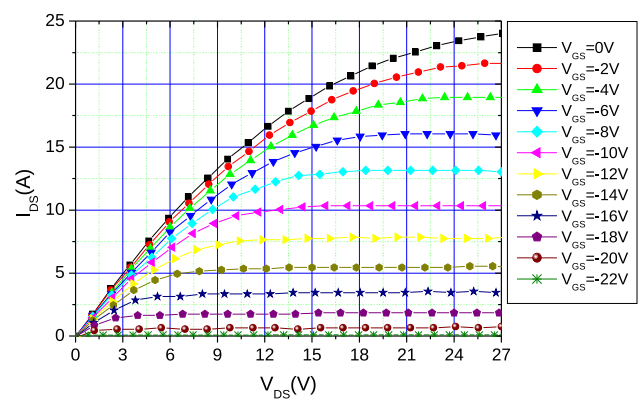

(b)

Figure 2: Static characteristic of a $1200 \mathrm{~V}-15 \mathrm{~A}-200 \mathrm{~m} \Omega$ JFET (third generation) from SiCeD, for two ambiant temperatures: (a) $25^{\circ} \mathrm{C}$ and (b) $225^{\circ} \mathrm{C}$. Curves where acquired using a Tektronix 371 curve tracer in pulse mode. Please note that both curves have a different $y$-scale for the sake of readability.

Regarding controlled switches, MOSFET have not reached yet maturity: their oxide layer has poor reliability under high temperature and high voltage; the carrier mobility in their channel is low, and charge trapping in the gate oxide causes threshold voltage instability [11]. Apparently, some of these limitations have been overcome recently, as SiC MOSFETs operating above $200^{\circ} \mathrm{C}$ have been demonstrated [12], but without any information about reliability and ageing.

Currently, JFETs are considered good candidates as the "general purpose" SiC controlled switch. They are available as engineering samples (for example from SiCeD, see figure 2), and should be commercially available soon. Their main drawback is that they are "normally on", i.e. they conduct current when no voltage is applied between their gate and source terminals. This requires special care when designing a converter to ensure that a fault in the control circuit won't result in a short-circuit in the power side. Furthermore, it can be seen in figure 2 that JFETs require a negative voltage on the gate, whereas Si MOSFET require a positive voltage to turn on.

A SiC JFET/Low-voltage Si MOSFET hybrid has been presented to create a "normally-off" switch. This component is called a Baliga-pair [8] or a cascode. The presence of a Si-MOSFET, however, makes it ill-suited to high temperature.

\subsubsection{Bipolar devices}

As unipolar devices have quite good performances up to a few kilovolts, most of the work on bipolar devices is towards very high voltage (tens of kilovolts), for energy distribution applications (PiN diodes, BJT, thyristors). However, bipolar devices can be interesting for high temperature, even at low voltage, as their losses tend to reduce as temperature increases [13]. Furthermore, Bipolar Junction Transistors (BJTs) are normally-off devices, which could make designing a converter easier (although they require fairly high current to drive them). Transic ${ }^{2}$ is an example of a company which sells BJTs for $600 \mathrm{~V}$ applications

Bipolar devices have long been crippled by defects in the base material (stacking faults).

\footnotetext{
2 http: //www.transic.com/
} 


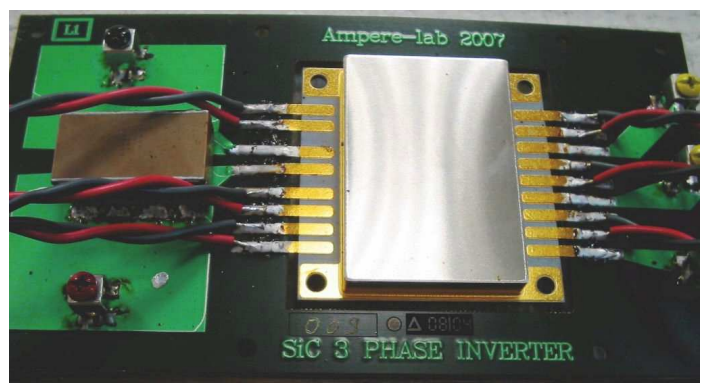

Figure 3: A JFET-based, 540 V, 15 A, 3-phase inverter (6 JFETs) in a single package with an external DC capacitor. This system has been successfully tested at $200^{\circ} \mathrm{C}$.

Their performances used to drop rapidly during operation. This is apparently getting better, and some bipolar devices have been found to be stable for long periods (although the quality of the base material still has a lot of influence) [14]

\subsection{High temperature converters}

Now that some SiC components have become available, some of the research work has shifted to high-temperature converters. As we will see below, active devices are just one of the many parts required to build a converter (high temperature passive, packaging, control circuits are also required).

As long as the ambient temperature remains under $150^{\circ} \mathrm{C}$, classical silicon control circuits can be used. This is the case with inverters designed for automotive hybrids, which make use of the ICE cooling loop $\left(120^{\circ} \mathrm{C}\right)$ [15]. In this case, it is possible to use Si IGBTs together with SiC SBDs, providing the thermal resistance of the package is low enough to keep the junction temperature of the IGBT below $175^{\circ} \mathrm{C}$.

In [16], an inverter operating at $150^{\circ} \mathrm{C}$ ambient temperature is presented. Here, the idea is to take advantage of $\mathrm{SiC}$ devices to allow the junction temperature to reach $250^{\circ} \mathrm{C}$. The $100^{\circ} \mathrm{C}$ temperature gradient allows to use a less efficient (and therefore much smaller) heatsink

At a even higher temperature $\left(200^{\circ} \mathrm{C}\right)$, a SiC MOSFET-based, 2-kW boost converter is demonstrated [12] . In [17], authors have designed all the basic building blocks for a JFET driver, to be built in SOI. These blocks (in discrete form) have been used to drive a JFET-based inverter operating at $200^{\circ} \mathrm{C}$ ambient temperature [18]. A picture of the inverter can be seen in figure 3

Finally, in [19], a buck converter (SiC JFET and SBD) is tested at $400^{\circ} \mathrm{C}$. However, due to the very high leakage current in the SBD at high temperature, the converter is derated to $200 \mathrm{~V}$ instead of $600 \mathrm{~V}$. Moreover, the saturation current in the JFET drops from 3.5 A to $0.7 \mathrm{~A}$ at high temperature. Also, some components, such as the control circuits and the input capacitor are kept at ambient.

\section{Remaining issues}

As we have seen, some of the basic building block for high temperature power converters have become available in recent years. Although the first demonstrators have been presented, re- 


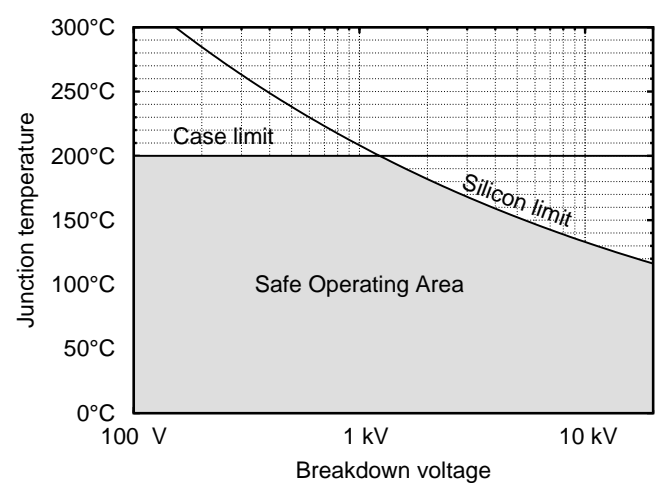

Figure 4: For low-voltage silicon devices, the maximum operating temperature is limited by the materials of the case. For higher voltage devices, the limit is the silicon.

search is still ongoing to provide systems with better performances, and more important yet, better reliability.

\subsection{Better $\mathrm{SiC}$ devices}

At the moment, only SiC SBD have reached maturity.

MOSFETs have only been demonstrated by a few research laboratory, with little information about their reliability.

JFETs are getting better, but some of their parameters (such as the threshold voltage) are not fully controlled yet. Because of this, drivers must be individually matched to the transistors (the gate breakdown voltage is only a few volts away from the threshold voltage). This should improve soon.

The gain of BJTs is still relatively low (in the order of 30). This puts a lot of constraints on the driver, which has a lot of current to source. Darlington pairs or more advanced combination should improve this issue.

\section{2 high temperature/reliability packaging}

As can be seen in figure 4, even for silicon devices, the maximum operating temperature is sometimes limited by the packaging. Most packaging solutions have indeed been developed for mild ambient [20], and require a complete redesign to cope with high temperature environments.

An example of this is the die-attach solution: in classical power modules, it is made using the so-called "high temperature" lead-rich solder alloy [20], which melts at $312^{\circ} \mathrm{C}$, or with other alloys which have an even lower melting point [21]. Although the melting point is higher than most high temperature environments, a wide safety margin must be ensured between the maximum operating temperature and the melting point: the closer you are to the melting point, the worse the mechanical properties of the solder alloy. In most cases, the homologous temperature (ratio of the melting point over the operating temperature, both expressed in Kelvin) should not exceed 0.67 (although values as high as 0.85 are not uncommon in electronics).

To avoid the use of very high-melting point solder alloys, which would put a lot of stress on semiconductor dice during assembly, different die-attach solutions have been explored. Sintering of micrometre-sized silver powder has been developed by Semikron [22]. With this 


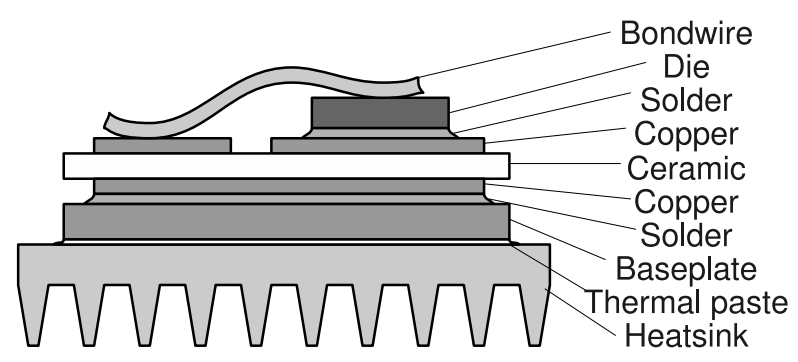

Figure 5: Cross section of a power module (with its associated heatsink), which shows the many layers and interfaces it contains. When this structure is submitted to power cycling, heavy mechanical stresses are generated and can eventually yield to fatigue and faillure of the assembly.

technique, a joint is obtained by applying pressure (40 MPa) and temperature (about $250^{\circ} \mathrm{C}$ ). As the die-attach material is pure silver, its melting point is expected to be $961^{\circ} \mathrm{C}$, and therefore will operate at very low homologous temperature. To avoid the use of pressure (which requires dedicated tooling), researchers at the Virginia Tech. have presented a silver sintering solution using nanometre-sized powder [23],[24]. This solution gives good results compared to Epoxy-based die attach or Au-Ge solders [25].

Another approach is the Transient Liquid Phase Bonding (TLP)[26]. With this technique, a low-melting point metal (or alloy) will diffuse into a solid phase. Once it is completely diluted into the solid phase, the melting point of the newly formed alloy will be much higher than the process temperature. Such techniques have been applied to Au/Sn alloys [27], In/ $\mathrm{Ag}$ [28], among others. Finally, more exotic solutions have been explored to create a very localised heating (hence avoiding stressing the dice) by using "explosive" reactive die attach [29].

In addition to the temperature-limitation of many parts of a classical packaging such as depicted in figure 5 (solders, wirebonds, silicone encapsulant, thermal paste...), it must be noted that power modules are very sensitive to thermal cycling. As we can see in figure 5, a power module is a stack of many materials, creating many interfaces. When such stack is submitted to thermal cycling, all parts tends to expand differently (as they all have different coefficients of thermal expansion), creating stresses at the interfaces. During the life of the power module, part of these stresses accumulates, creating fatigue and eventually failure. This phenomenon is already present with standard, silicon-based components, but becomes even more visible with high-temperature applications.

\subsection{High temperature control circuits}

Most high temperature converter use control circuits made with Silicon-On-Insulateor (SOI) substrate. Many circuits have been developed by Honeywell for oil well applications [7]. In Europe, the company Cissoid $^{3}$ also designs SOI circuits for high temperature, including MOSFET drivers [30].

Recently, the first SiC-based integrated circuit has been announced [11]. It should eventually allow very high temperature drivers, or monolithic integration of drivers and power. However, a lot of work is still needed to produce a driver complete with power supply and device

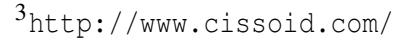


protections.

\subsection{High temperature passives}

Magnetic material can be found for ambient temperature up to $450^{\circ} \mathrm{C}$ [19]. Capacitors are much of an issue, as most dielectric material cannot be used above 200 to $250^{\circ} \mathrm{C}$. For example, mica can be used up to $260^{\circ} \mathrm{C}$, TFE up to $200^{\circ} \mathrm{C}$ [31]. A common dielectric in ceramic capacitors (X7R) can also be used at $200{ }^{\circ} \mathrm{C}$, but at the expense of a strongly reduced capacitance (around $50 \%)$. For all these technologies, the dissipation factor is high (1\%), as well as the cost for capacitors rated at a few hundred volts.

\section{Conclusion}

Silicon carbide allows power devices operating at very high temperature (in theory more than $1000^{\circ} \mathrm{C}$ ). As we have seen, research is still needed to take fully advantage of this material. Packaging, passive components and control circuits are currently restricted to much lower temperatures. Research is also needed to produce better power devices, eventually using alternative wide-bandgap semiconductors, such as GaN or diamond.

The first demonstrators of high temperature converters have been presented recently. They prove the feasibility and the advantages of systems that can operate in harsh environments.

\section{References}

[1] M. Consortium, "Project year 1 executive summary," report, MOET FP6, sep 2007.

[2] I. S. Mehdi, A. E. Brockschmidt, and K. K. J., "A case for high temperature electronics for aerospace," in Proceedings of the High Temperature Electronics Conference (HiTEC), (Santa Fe, NM), IMAPS, may 2006.

[3] J. G. Kassakian and D. J. Perreault, "The future of electronics in automobiles," in Proceedings of the International Symposium on Power Semiconductor Devices and ICs (ISPSD), (Osaka, Japan), pp. 15-19, 2001.

[4] L. D. Marlino, "High temperature \& thermal management needs for the freedomcar program," in Proceedings of the High Temperature Electronics Conference (HiTEC), (Santa Fe, NM), IMAPS, may 2006.

[5] E. Kolawa, M. Mojarradi, and T. Balint, "Applications of high temperature electronics in space exploration," in Proceedings of the High Temperature Electronics Conference (HiTEC), IMAPS, may 2006.

[6] "Downhole gas compression," product brochure, Corac Group plc, 2005.

[7] B. W. Ohme, M. R. Larson, J. Riekels, S. Schlesinger, K. Vignarajah, and E. M. Nance, "Progress update on honeywell's deep trek high temperature electronics project," in Proceedings of the High Temperature Electronics Conference (HiTEC), (Santa Fe), p. 9, IMAPS, may 2006.

[8] B. J. Baliga, "The future of power semiconductor device technology," Proceedings of the IEEE, vol. 89, pp. 822-832, jun 2001.

[9] T. Funaki, J. C. Balda, J. Junghans, A. Jangwanitlert, S. Mounce, F. D. Barlow, H. A. Mantooth, T. Kimoto, and T. Hikihara, "Switching characteristics of sic jfet and schottky diode in high-temperature dc-dc power converters," IEICE Electronics Express, vol. 2, pp. 97-102, feb 2005.

[10] A. Ward, "Sic power diode reliability," application note, CREE, 4600, Silicon Drive, Durham, NC, oct 2008.

[11] K. Sheng, Y. Zhang, M. Su, J. H. Zhao, X. Li, P. Alexandrov, and L. Fursin, "Demonstration of the first sic power integrated circuit," Solid State Electronics, vol. 52, pp. 1636-1646, 2008.

[12] B. Ray, J. D. Scofield, R. L. Spyker, B. Jordan, and S.-H. Ryu, "High temperature operation of a dc-dc power converter utilizing sic power devices," in Proceedings of the $20^{\text {th }}$ Applied Power Electronics Conference (APEC), (Austin, TX), pp. 315-321, IEEE, mar 2005. 
[13] P. Borthen and G. Wachutka, "Testing semiconductor devices at extremely high operating temperatures," Microelectronics Reliability, vol. 48, pp. 1440-1443, aug 2008. 19th European Symposium on Reliability of Electron Devices, Failure Physics and Analysis (ESREF 2008).

[14] P. G. Muzykov, R. M. Kennedy, Q. J. Zhang, C. Capell, A. Burk, A. Agarwal, and T. S. Sudarshan, "Physical phenomena affecting performance and reliability of $4 \mathrm{~h}-$ sic bipolar junction transistors," Microelectronics Reliability, vol. In Press, Corrected Proof, pp. -, 2008.

[15] C. Buttay, J. Rashid, C. Mark Johnson, P. Ireland, F. Udrea, G. Amaratunga, and R. Malhan, "High performance cooling system for automotive inverters," in Proc. European Conference on Power Electronics and Applications, (Aalborg, Denmark), pp. 1-9, EPE, sep 2007.

[16] J. M. Hornberger, E. Cilio, R. M. Schupbach, A. B. Lostetter, and H. A. Mantooth, "A high-temperature multichip power module (mcpm) inverter utilizing silicon carbide (sic) and silicon on insulator (soi) electronics," in Proceedings of the $37^{\text {th }}$ Power Electronics Specialists Conference (PESC), (Jeju, Korea), pp. 9-15, IEEE, June 2006.

[17] D. Bergogne, H. Morel, D. Tournier, B. Allard, D. Planson, C. Raynaud, and M. Lazar, "Normally-on devices and circuits, sic and high temperature : using sic jfets in power converters," in Proceedings of the $5^{\text {th }}$ Conference on Integrated Power Systems (CIPS), 2008.

[18] D. Bergogne, H. Morel, D. Planson, D. Tournier, P. Bevilacqua, B. Allard, R. Meuret, S. Vieillard, S. Raël, and F. Meibody Tabar, "Towards an airborne high temperature sic inverter," in Proceedings of the Power Electronics Specialists Conference (PESC), IEEE, 2008.

[19] T. Funaki, J. C. Balda, J. Junghans, A. S. Kashyap, H. A. Mantooth, F. Barlow, T. Kimoto, and H. Takashi, "Power conversion with sic devices at extremely high ambient temperatures," IEEE Transactions on Power Electronics, vol. 22, pp. 1321-1329, jul 2007.

[20] W. W. Sheng and R. P. Colino, Power Electronic Modules: Design and Manufacture. CRC, 1st ed., jun 2004.

[21] I. Corp, “Alloy sorted by temperature," datasheet, Indium Corp.

[22] C. Göbl, P. Beckedahl, and H. Braml, "Low temperature sinter technology die attachment for automotive power electronic applications," in Automotive Power Electronics, (Paris), p. 5, 21-22 jun 2006.

[23] G. Bai, Low-Temperature Sintering of Nanoscale Silver Paste for Semiconductor Device Interconnection. PhD thesis, Virginia Polytechnic Institute and State University, Blacksburg, Virginia, oct 2005.

[24] J. G. Bai, J. Yin, Z. Zhang, G.-Q. Lu, and van Wyk Jacobus Daniel, "High-temperature operation of sic power devices by low-temperature sintered silver die-attachment," IEEE Transactions on Advanced Packaging, vol. 30, pp. 506-510, aug 2007.

[25] R. Kisiel and S. Z., "Die-attachment solutions for sic power devices," Microelectronics Reliability, vol. In Press, Corrected Proof, 2009.

[26] J. Roman and T. Eagar, "Low stress die attach by low temperature transient liquid phase bonding," in 1992 International Symposium on Microelectronics (I. International Society for Hybrid Microelectronics, ed.), no. 52, (San Fransisco, California), 1992.

[27] R. W. Johnson, C. Wang, Y. Liu, and J. D. Scofield, "Power device packaging technologies for extreme environments," IEEE Transactions on Electronics Packaging Manufacturing, vol. 30, pp. 182-193, jul 2007.

[28] T. Quintero, Pedro O. andy Oberc and F. P. McCluskey, "High temperature die attach by transient liquid phase sintering," in HiTEC 2008, (Albuquerque), pp. 207-212, IMAPS, may 2008.

[29] A. McClure, P. McCluskey, and A. J. Clark, "Rapid thermal processed attachment materials," in HiTEC 2008, (Albuquerque), pp. 273-278, IMAPS, May 2008.

[30] CISSOID, "High-temperature, bootstrapped full-bridge mosfet driver," datasheet, CISSOID, sep 2008.

[31] J. S. Bowers, "Comparative characterization of capacitors used in high temperature electronics applications," in Proceedings of the $4^{\text {th }}$ High Temperature Electronics Conference (HiTEC), pp. 184-190, IMAPS, 1998. 